\title{
Estrogen-related receptors in breast cancer and prostate cancer
}

\author{
Aya Misawa ${ }^{1}$ and Satoshi Inoue ${ }^{1,2 *}$ \\ ${ }^{1}$ Department of Anti-Aging Medicine, Graduate School of Medicine, The University of Tokyo, Tokyo, Japan, ${ }^{2}$ Division of Gene \\ Regulation and Signal Transduction, Research Center for Genomic Medicine, Saitama Medical University, Saitama, Japan
}

Estrogen-signaling pathways are implicated in the development of breast cancer and prostate cancer. Various studies have focused on additional signaling pathways, mediated by estrogen-related receptors (ERRs). ERRs are constitutively active receptors that share a high degree of homology with the classical estrogen receptors (ERs). However, they do not bind to estrogen, while ERs do. ERRs are involved in the development of alternative pathways that lead to the development of cancer and are regarded as potential therapeutic targets for the treatment of breast cancer and prostate cancer that do not respond to conventional therapies. In this review, we first present general structural features of ERRs. Then, we focus on breast cancer and prostate cancer, which are

OPEN ACCESS

Edited by:

Jessica Kate Holien,

St. Vincents Institute of Medical

Research, Australia

Reviewed by:

Maria Marino,

Universita degli Studi Roma Tre, Italy Domenico lacopetta,

University of Calabria, Italy

*Correspondence:

Satoshi Inoue,

Department of Anti-Aging Medicine, Graduate School of Medicine, The University of Tokyo, 7-3-1 Hongo Bunkyo-ku, Tokyo 113-8655, Japan inoue-ger@h.u-tokyo.ac.jp

Specialty section: This article was submitted to Cancer Endocrinology, a section of the journal Frontiers in Endocrinology

Received: 12 March 2015 Accepted: 05 May 2015 Published: 26 May 2015

Citation:

Misawa A and Inoue S (2015) Estrogen-related receptors in breast cancer and prostate cancer.

Front. Endocrinol. 6:83.

doi: 10.3389/fendo.2015.00083 primarily hormone-dependent cancers, and summarizes recent progress in elucidating the involvement of each ERR in these two types of malignancies.

Keywords: estrogen-related receptors, estrogen receptors, estrogen, androgen, breast cancer, prostate cancer

\section{Introduction}

Among the 48 members of the nuclear receptor superfamily, the estrogen receptor (ER)-like subfamily (NR3) is one of the seven subfamilies and is composed of three groups: ERs(NR3A), estrogen-related receptors (ERRs or NR3B), and 3-ketosteroid receptors (NR3C), which include the androgen receptor (AR), progesterone receptor (PR), glucocorticoid receptor (GR), and mineralocorticoid receptor (MR). ERRs were initially thought to share a common biological function with ERs, but unexpectedly, they do not bind to estrogen or endogenous ER ligands and are considered orphan nuclear receptors (1).

Estrogens are natural hormones considered to play a major role in promoting the proliferation of both the normal and neoplastic breast epithelium. Growing evidences suggest that estrogensignaling pathways are implicated in not only in the development of breast cancer but also in that of prostate cancer, which are both hormone-dependent cancers (2). ER-positive breast cancers are preferentially treated with antiestrogens such as selective ER modulators known as SERMs (including tamoxifen which is the most commonly used) or selective ER down-regulators known as SERDs (ICI 182,780) (3). Aromatase inhibitors are used in postmenopausal women to block the enzyme aromatase, which is involved in the final step of estrogen synthesis from circulating androgens (4). Androgen deprivation therapy (ADT) is used for the treatment of locally advanced, biochemically recurrent, and metastatic prostate cancer. However, after the initial response, these therapies for breast and prostate cancer fail and cancer will inevitably recur (5-7). The mechanisms underlying recurrence have not been fully clarified, but the acquisition of alternative intracellular ER signaling may be involved in hormonal therapy resistance.

Various studies have focused on additional estrogen-related signaling pathways, mediated by ERRs (8-10). Sequence analysis reveals that ERRs and the classical ERs share a high degree of 
homology within their DNA and ligand-binding domains (LBDs) (11). The ERR family consists of three closely related members: $\operatorname{ERR} \alpha, \operatorname{ERR} \beta$, and $\operatorname{ERR} \gamma$ (Figure 1). ERRs, like other nuclear receptors, consist of six conserved regions (A-F): A/B domain containing the $\mathrm{N}$-terminal domain (NTD), $\mathrm{C}$ domain with a DNA binding domain (DBD), D domain, which corresponds to the hinge region, $\mathrm{E}$ domain containing a putative $\mathrm{LBD}$, and the $\mathrm{F}$ domain or $\mathrm{C}$-terminal region. The transcriptional activation function-1 (AF-1) site is located in the N-terminal A/B domain, and its activity does not depend on the presence of activating ligands. The ligand-regulated activation function-2 (AF-2) site is located at $\mathrm{E}$ domain and it is known to synergize with AF-1 to regulate gene expression $(12,13)$. These receptors are constitutively active due to the structure of the LBD that leaves the AF-2 exposed and capable of binding coregulators in the absence of ligand binding.

\section{ERR Action Mechanisms}

Like other nuclear receptors, the transcriptional activity of ERRs is dependent on the presence of coregulatory proteins, either corepressors or coactivators. Steroid receptor coactivator (SRC)$1,-2$, and -3 , which regulate hepatic metabolism, fat storage, and energy balance, have been shown to interact with one or more ERR isoform stimulating their transcriptional activity $(14,15)$. PPAR $\gamma$ coactivator (PGC)-1 $\alpha$ and PGC-1 $\beta$, which play essential roles in metabolic programs, have been shown to directly interact with ERRs, positively regulating the expression and activity or these nuclear receptors (16). The activity of the ERRs as transcription factors is generally inhibited through physical interaction with receptor interacting protein 140, RIP140, also known as nuclear receptor interacting protein 1 , NRIP1, a corepressor that competes for interaction with PGC-1 $\alpha$ for ERRs binding negatively regulating gene expression (17).

Estrogen-related receptors can bind to DNA on ERR response elements (ERREs) designated by the sequence $5^{\prime}$-TNAAGGTCA$3^{\prime}$ as well as the classical ER response elements (EREs) $5^{\prime}$ AGGTCANNNTGACCT- $3^{\prime}$, where $\mathrm{N}$ represents any nucleotide (18-20). These orphan nuclear receptors play a central role in regulating cellular metabolism through the regulation of genes involved in glycolysis, oxidative phosphorylation, and tricarboxylic acid cycle (21). ERR $\alpha$ is present in tissues with high metabolism, such as the heart, kidney, intestinal tract, skeletal muscle, and brown adipose tissue (22). The expression of ERR $\beta$ and ERR $\gamma$ is more restricted, being mainly expressed in the heart and kidney $(22,23)$. Both ERR $\alpha$ and ERR $\gamma$ are upregulated in preadipocytes and pluripotent mesenchymal cells under adipogenic conditions, positively regulating lipid accumulation $(24,25) . \operatorname{ERR} \beta$ and ERR $\gamma$ are also expressed during the early embryonic development and in the central nervous system and spinal cord. Although ERRs have structural and functional similarities, mice deficient for each ERR exhibit different phenotypes, suggesting that these ERRs have specific and unique functions. ERR $\alpha$-deficient mice are viable, but exhibit a phenotype characterized by reduced body weight, peripheral fat deposits, and resistance to high-fat diet-induced obesity (26). They also exhibit a loss of normal mitochondrial biogenesis (27). On the other hand, ERR $\beta$-deficient mice are lethal due to impaired placenta formation (28). Interestingly, an important role of this orphan receptor in embryonic stem (ES) cells maintenance has been suggested,

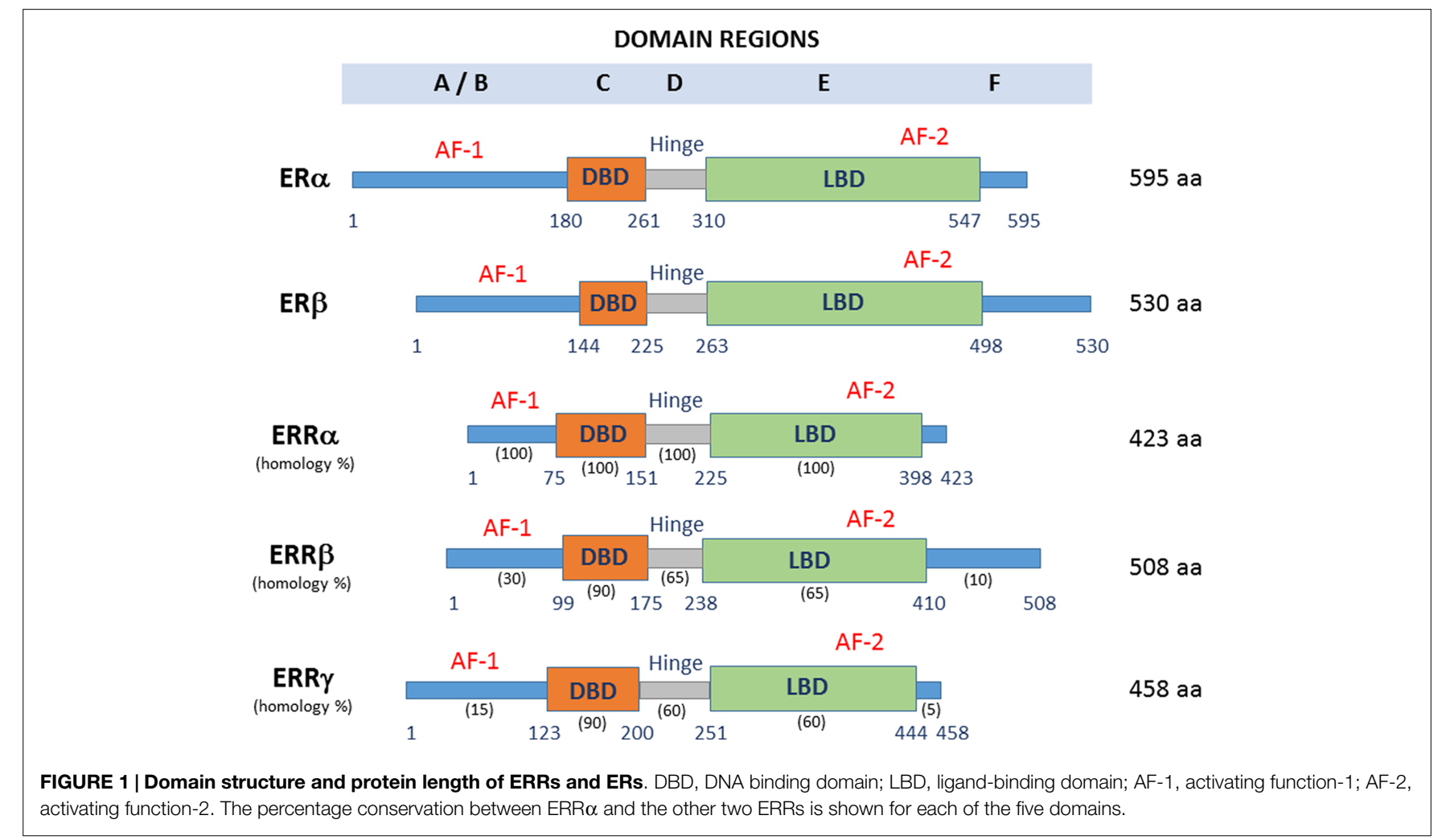


as it is able to regulate self-renewal in ES cells in cooperation with octamer-binding protein 4, Oct4, and sex determining region Y-box 2, Sox2, replacing kruppel-like factor 4, Klf4, and consequently enhancing the transcription of reprograming factors (29). ERR $\gamma$-deficient mice also die during the early postnatal period due to abnormal heart function (30). It has been reported that ERR overexpression increases glycolysis, while depletion results in the opposite effect, reducing aerobic glycolysis (31). Furthermore, ERR $\alpha$ and ERR $\gamma$ were found to form heterodimers and bind to the promoters of the same target genes to regulate genes controlling both the glycolytic and the oxidative mitochondrial respiration phenotypes (32). These findings suggest that ERRs might contribute to a shift in cellular metabolism from normal mitochondrial oxidative phosphorylation to an aerobic glycolysis typical of cancer cells, known as the Warburg effect, increasing glucose consumption, and ATP production (33). However, a number of evidence suggest that ERR $\alpha$ and ERR $\gamma$ have opposite functions in regulating cellular metabolism. ERR $\alpha$ could assist in setting a glycolytic profile required for the proliferation of rapidly dividing cells in normal tissues with high-energy demand and tumors consequently promoting cellular proliferation (34-39). By contrast, ERR $\gamma$ high expression has been detected in tumors with better prognosis (36), and inhibition of this orphan receptor by a microRNA (miR-378*) induces a metabolic switch by promoting a Warburg-like phenotype (40). These findings illustrates the complexity of metabolic reprograming by ERRs in cancer cells, where ERR $\alpha$ and ERR $\gamma$ could cooperate or play an opposite role in the metabolic transcriptional pathway depending on the cellular environment and the expression of distinct coregulators (41) (Table 1).

\section{ERRs in Breast Cancer}

Breast cancer is the leading cause of cancer-related death in women worldwide (50). It is primarily a hormone-dependent disease that can be regulated by the status of steroid hormones such as estrogen and progesterone. Unfortunately, the emergence of hormone-resistant tumor cells after years of treatment is a major issue affecting patients with breast cancer (7). Breast cancers can be divided into five subtypes that vary in their treatment options and survival outcomes based on gene expression profiles (51-54). ER $\alpha$ positive $(\mathrm{ER} \alpha+)$ and progesterone receptor positive $(\mathrm{PR}+)$ tumors account for approximately $70 \%$ of all cases $(55,56)$. These $\mathrm{ER} \alpha+/ \mathrm{PR}+$ tumors can be further classified into HER2 + and HER2 - subtypes depending on epidermal growth factor receptor 2, ErbB-2, or HER2 gene expression. Blocking the estrogen production or estrogen binding to the receptor by tamoxifen or aromatase inhibitors is the standard treatment for both early and advanced ER $\alpha+$ breast cancer $(57,58)$. For ER $\alpha$ negative $(\mathrm{ER} \alpha-)$, progesterone receptor negative $(\mathrm{PR}-)$, and HER $2+(\mathrm{ER} \alpha-/ \mathrm{PR}-/ \mathrm{HER} 2+)$ breast tumors, a combination of pertuzumab, trastuzumab, and docetaxel has been effective (59). However, there are still no approved targeted therapies for triple negative ER $\alpha-/ P R-/ H E R 2$ - breast tumors (10-17\% of all breast cancer cases) $(60,61)$, or the normal breast-like or basal-like cancer subtype ( $15 \%$ of the cases) $(62,63)$, which are mostly triple negative and frequently have TP53 mutations (64).

Much attention has been paid to the role of ERRs in breast cancer, as they are orphan nuclear receptors closely related to ERs. ERR $\alpha$ expression in breast tumors is often high, and it is expressed in tumors with poor prognosis (36). In samples from various cohorts of patients with breast cancer, ERR $\alpha$ mRNA positively correlates with the expression of the oncogene ERBB2 and inversely correlates to that of $\mathrm{ER} \alpha$ and $\mathrm{PR}$, which are considered as good prognostic markers for patients with breast cancer (36). The expression of ERR $\alpha$ mRNA and protein positively correlates with the coactivator amplified in breast cancer 1 (AIB1), also known as SRC-3 (65). However, ERR $\alpha$ is able to act as both a transcriptional activator and repressor depending on the cellular context, promoting or inhibiting tumor growth in breast cancer (42). In ER - breast cancer cells, ERR $\alpha$ functions as a transcriptional activator constitutively interacting with coactivators and binding to EREs independently of any ligands. Consequently, $\mathrm{ERR} \alpha$ competes with ER in the regulation of estrogen-responsive genes such as the estrogen-regulated trefoil factor 1 (TFF1) (65, 66) and vascular endothelial growth factor (VEGF) $(34,43)$. In $\mathrm{ER}+$ breast cancer cells, ERR $\alpha$ functions as a transcriptional repressor, interacting with corepressors and binding to negative EREs (42).

$\mathrm{ERR} \alpha$ also plays a role in bone metastasis, which occurs in up to $70 \%$ of patients with advanced breast cancer (44). In a mouse xenograft model of metastatic human breast cancer, overexpression of wild-type ERR $\alpha$-reduced metastasis and breast cancer cell growth in the bone, likely by upregulating the osteoclastogenesis inhibitor, osteoprotegerin (OPG). By contrast, ERR $\alpha$ overexpression increases breast cancer cell growth in the mammary gland and the expression of VEGF. Thus, ERR $\alpha$ plays dual roles, promoting the progression and invasion of primary tumors by decreasing osteolytic lesions in the bone (44).

It has been suggested that the induction of $c$-myc expression by estrogen occurs through the "non-classical" pathway without binding of ER $\alpha$ to its promoter (67). Another study demonstrated a positive correlation between ERR $\alpha, c-m y c$, and aromatase (37), an enzyme that may enhance estrogen production and stimulate breast cancer progression (38). These studies propose that ERR could play an important role in alternative

TABLE 1 | Expression of ERR isoforms and implication in breast cancer and prostate cancer

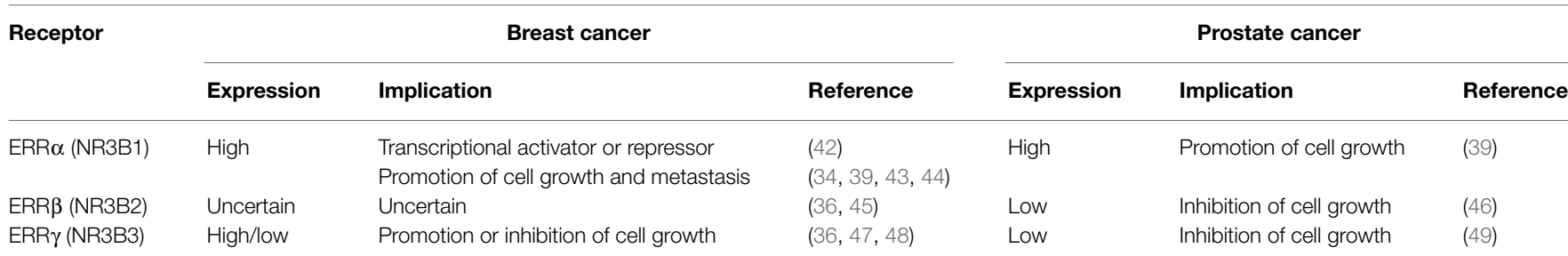


pathway to classical ERs-dependent pathway in cell signaling through aromatase and $c-m y c$.

ERR $\alpha$ participates in the enhancement of estrogen production by the activation of steroid sulfotransferase (SULT2A1), which maintains high level of peripheral dehydroepiandrosterone sulfate (DHEAS), an important dehydroepiandrosterone (DHEA) metabolite in estrogen synthesis in certain tissues (68). It has also been reported that SULT2A1 inactivates tamoxifen and raloxifene (69). Thus, SULT2A1 activation by ERR $\alpha$ can partly explain the resistance of breast cancer cells expressing ERR $\alpha$ to SERM therapy.

A clinical study analyzing 102 breast cancer samples revealed that the expression of ERR $\alpha$ in more than $10 \%$ of malignant cells was associated with a $20 \%$ decrease in overall disease survival at 13 years (70). In this work, association between ER $\alpha$ and ERE-containing estrogen-responsive genes was markedly altered according to ERR $\alpha$ status in breast cancer tissues, suggesting that ERR $\alpha$ possibly modulates ER $\alpha$-mediated and ERE-dependent transcription, and changes the expression of estrogen-responsive genes in breast cancer cells. In a previous clinical study, high levels of ERR $\alpha$ mRNA correlated with ER $\alpha$-tumor status in 38 tumor specimens (36). These two studies suggest that ERR $\alpha$ mRNA and protein expression are associated with an unfavorable prognosis, and increase the risk of recurrence of breast cancer.

ERR $\gamma$ also acts differently depending on ER expression. In breast tumors co-expressing ER and PR, ERR $\gamma$ induces E-cadherin expression and promotes the mesenchymal-to-epithelial (MET) transition, resulting in the inhibition of tumor growth $(36,47)$. It has been shown that an AAG tetranucleotide polymorphism in the untranslated region of the $E R R \gamma$ gene is associated with breast cancer predisposition (71), and that ERR $\gamma$ mediates tamoxifen resistance in invasive lobular breast cancer. In human breast cancer specimens, both ERR $\gamma$ mRNA and protein expression are upregulated compared with normal samples, and exogenously transfected ERR $\gamma$ increased breast cancer cell proliferation (36, 48). Tumors overexpressing ERR $\gamma$ are also frequently steroid receptor positive, which may reflect hormonal sensitivity and a preferable clinical outcome. Thus, ERR $\gamma$ mRNA expression is associated with a favorable prognosis of patients with breast cancer (36).

ERR $\beta$ expression has also been detected in breast tumors. It has been shown that ERR $\beta$ expression is associated with that of $\operatorname{ER} \beta$, and that ERR $\beta$ levels inversely correlate with the S-phase fraction, suggesting that this orphan receptor inhibits cellular proliferation, or possibly promotes cellular differentiation (36). However, another report found that it acts as a proliferative gene (45). Thus, the potential role of ERR $\beta$ in breast cancer remains unclear.

\section{ERRs in Prostate Cancer}

Prostate cancer, which is dependent on androgens for proliferation and survival, is the second-leading cause of cancer-related mortality, after lung cancer, in men from developed countries (72). With early diagnosis, radical prostatectomy and/or radiation therapy are potentially curative. For advanced or metastatic prostate cancer, hormonal therapies, reducing androgen levels by surgical or chemical castration or inhibiting the AR protein by small molecules, are used (57). However, after an initial response, the cancer eventually recurs in an incurable, castrationresistant form $(5,6)$, as a result of amplification of AR protein, mutations of $A R$ gene, and elevated production of $\mathrm{AR}$ variants (73).

In addition to androgen-signaling pathways, estrogensignaling pathways are implicated in the development of prostate cancer (1), and estrogen has been used for the treatment of advanced prostate cancer (74). The direct effect of estrogens on normal and malignant prostate tissues is assumed to be mediated through $\operatorname{ER} \alpha$ and $\operatorname{ER} \beta(75,76)$.

$\mathrm{ERR} \alpha \mathrm{mRNA}$ has been detected in prostate cancer cell lines and human prostate cancer tissue (77). Although a heterogeneous ERR $\alpha$ staining was found in immunohistochemical analysis using prostate cancer tissues with low Gleason score (GS), increased ERR $\alpha$ protein expression was detected in human prostate tissue from 106 surgical resected prostate samples in a study that showed a positive correlation between ERR $\alpha$ expression and GS (78). The enhanced expression of ERR $\alpha$ might play a role in the development of human prostate cancer and serve as a significant prognostic factor for the disease.

By contrast, reduced ERR $\beta$ and ERR $\gamma$ expression in some prostatic carcinomas has been reported (77), and overexpression of ERR $\beta$ or ERR $\gamma$ results in the suppression of cell proliferation in both androgen-sensitive and insensitive prostate cancer cells, suggesting that these receptors present antiproliferative or tumorsuppressing functions in prostate cancer $(46,49)$. Furthermore, it has been shown that $\operatorname{ERR} \beta$ directly transactivates a promoter upstream of the cyclin-dependent kinase inhibitor, p21 gene, resulting in the inhibition of the cell cycle progression (46). Clinicopathological studies for the expression of both orphan receptors in human prostate tissues have been performed using immunohistochemical analysis (79). Cancerous lesions and benign foci obtained from radical prostatectomy were stained and immunoreactivity scores (IR scores) were evaluated from the proportion of immunoreactive cells and staining intensity, revealing that ERR $\beta$ and ERR $\gamma$ IR scores are significantly lower in cancerous tissues. In the same study, patients with high ERR $\alpha$ IR score, but low ERR $\gamma$ IR score, presented a poorer cancer-specific survival when compared to the other group, suggesting that the expression of ERR $\beta$ and ERR $\gamma$ could be a useful prognostic indicator of prostate cancer (79).

\section{ERRs Agonists and Antagonists}

Although no endogenous ligands have been identified for these receptors several natural phytoestrogens (three isoflavones: genistein, daidzein, and biochanin $\mathrm{A}$, and one flavone: 6, 3, 4trihydroxyflavone) have been identified as potential ligands of these receptors with agonistic activities, by structure-based virtual screening and biological functional assays $(80,81)$. Phytoestrogens are produced by plants, and represent the major natural exogenous sources of estrogenic compounds. DY131 is another ERR agonist, specific to ERR $\beta$ and ERR $\gamma$ that was shown to enhance growth inhibition, which was caused by overexpression 
of these nuclear receptors $(46,49)$. Inhibition of ERR $\alpha$ with the inverse agonist XCT790 reduces cell proliferation of various cancer cell lines, including prostate and breast cancer cells (39).

On the other hand, diethylstilbestrol (DB00255) and the tamoxifen metabolite, 4-hydroxytamoxifen, have been shown to interact with ERR $\beta$ and ERR $\gamma$ and act as antagonists $(82,83)$. SR16388, a novel steroidal antiestrogen, inhibits the interaction between its coactivator peroxisome proliferator-activated receptor $\gamma$ coactivator- $1 \alpha$ to inhibit ERR $\alpha$ activity (84).

\section{Conclusion}

Although the role of orphan nuclear receptors in cancer is becoming clearer as a result of advances in previous studies, their function still remains to be elucidated. A better understanding of ERRs in breast and prostate cancer will provide new insights into cancer biology as well as the discovery of novel small molecules that bind to these orphan receptors. This knowledge will be helpful for the

\section{References}

1. Roshan-Moniri M, Hsing M, Butler MS, Cherkasov A, Rennie PS. Orphan nuclear receptors as drug targets for the treatment of prostate and breast cancers. Cancer Treat Rev (2014) 40:1137-52. doi:10.1016/j.ctrv.2014.10.005

2. Bonkhoff $\mathrm{H}$, Berges R. The evolving role of oestrogens and their receptors in the development and progression of prostate cancer. Eur Urol (2009) 55:533-42. doi:10.1016/j.eururo.2008.10.035

3. Howell SJ, Johnston SR, Howell A. The use of selective estrogen receptor modulators and selective estrogen receptor down-regulators in breast cancer. Best Pract Res Clin Endocrinol Metab (2004) 18:47-66. doi:10.1016/j.beem.2003. 08.002

4. Smollich M, Gotte M, Fischgrabe J, Radke I, Kiesel L, Wulfing P. Differential effects of aromatase inhibitors and antiestrogens on estrogen receptor expression in breast cancer cells. Anticancer Res (2009) 29:2167-71.

5. Egan A, Dong Y, Zhang H, Qi Y, Balk SP, Sartor O. Castration-resistant prostate cancer: adaptive responses in the androgen axis. Cancer Treat Rev (2014) 40:426-33. doi:10.1016/j.ctrv.2013.09.011

6. Lonergan PE, Tindall DJ. Androgen receptor signaling in prostate cancer development and progression. J Carcinog (2011) 10:20. doi:10.4103/1477-3163. 83937

7. Ring A, Dowsett M. Mechanisms of tamoxifen resistance. Endocr Relat Cancer (2004) 11:643-58. doi:10.1677/erc.1.00776

8. Giguere V. To ERR in the estrogen pathway. Trends Endocrinol Metab (2002) 13:220-5. doi:10.1016/S1043-2760(02)00592-1

9. Horard B, Vanacker JM. Estrogen receptor-related receptors: orphan receptors desperately seeking a ligand. J Mol Endocrinol (2003) 31:349-57. doi:10.1677/ jme.0.0310349

10. Yang N, Shigeta H, Shi H, Teng CT. Estrogen-related receptor, hERR1, modulates estrogen receptor-mediated response of human lactoferrin gene promoter. J Biol Chem (1996) 271:5795-804. doi:10.1074/jbc.271.10.5795

11. Laudet V, Hanni C, Coll J, Catzeflis F, Stehelin D. Evolution of the nuclear receptor gene superfamily. EMBOJ (1992) 11:1003-13.

12. Tora L, Gronemeyer H, Turcotte B, Gaub MP, Chambon P. The N-terminal region of the chicken progesterone receptor specifies target gene activation. Nature (1988) 333:185-8. doi:10.1038/333185a0

13. Warnmark A, Treuter E, Wright AP, Gustafsson JA. Activation functions 1 and 2 of nuclear receptors: molecular strategies for transcriptional activation. $\mathrm{Mol}$ Endocrinol (2003) 17:1901-9. doi:10.1210/me.2002-0384

14. Karmakar S, Foster EA, Smith CL. Unique roles of p160 coactivators for regulation of breast cancer cell proliferation and estrogen receptor-alpha transcriptional activity. Endocrinology (2009) 150:1588-96. doi:10.1210/en. 2008-1001

15. Liu D, Benlhabib H, Mendelson CR. cAMP enhances estrogen-related receptor alpha (ERRalpha) transcriptional activity at the SP-A promoter by increasing identification of novel hormonal therapeutic strategies and cancer treatments.

\section{Acknowledgments}

We are grateful to Dr. K. Ikeda (Saitama Medical University) and Dr. K. Horie (Saitama Medical University) for critical reading of this manuscript and helpful suggestions. This work was supported by grants of the Cell Innovation Program and the P-DIRECT from the MEXT, Japan (SI), grants from JSPS, Japan (SI), and a grant of the Program for Promotion of Fundamental Studies in Health Sciences from NIBIO, Japan (SI). This work was supported by grants of the Cell Innovation Program (http://www. cell-innovation.org/) and the P-DIRECT (http://p-direct.mext. go.jp/) from the MEXT, Japan (S.I.), grants from JSPS KAKENHI (Grant Numbers 23249040 and 15K15353), Japan (S.I.), and a grant of the Program for Promotion of Fundamental Studies in Health Sciences from NIBIO (09-12), Japan (S.I.).

its interaction with protein kinase A and steroid receptor coactivator 2 (SRC-2). Mol Endocrinol (2009) 23:772-83. doi:10.1210/me.2008-0282

16. Skrzypczak M, Kapka-Skrzypczak L, Cyranka M, Treeck O, Wrobel A, Matosiuk D. Nuclear estrogen receptors co-activation mechanisms. Curr Med Chem (2013) 20:3317-38. doi:10.2174/09298673113209990006

17. Treuter E, Albrektsen T, Johansson L, Leers J, Gustafsson JA. A regulatory role for RIP140 in nuclear receptor activation. Mol Endocrinol (1998) 12:864-81. doi:10.1210/mend.12.6.0123

18. Pettersson K, Svensson K, Mattsson R, Carlsson B, Ohlsson R, Berkenstam A. Expression of a novel member of estrogen response element-binding nuclear receptors is restricted to the early stages of chorion formation during mouse embryogenesis. Mech Dev (1996) 54:211-23. doi:10.1016/0925-4773(95) 00479-3

19. Sladek R, Bader JA, Giguere V. The orphan nuclear receptor estrogen-related receptor alpha is a transcriptional regulator of the human medium-chain acyl coenzyme A dehydrogenase gene. Mol Cell Biol (1997) 17:5400-9.

20. Barry JB, Laganiere J, Giguere V. A single nucleotide in an estrogen-related receptor alpha site can dictate mode of binding and peroxisome proliferatoractivated receptor gamma coactivator 1alpha activation of target promoters. Mol Endocrinol (2006) 20:302-10. doi:10.1210/me.2005-0313

21. Deblois G, Giguere V. Oestrogen-related receptors in breast cancer: control of cellular metabolism and beyond. Nat Rev Cancer (2013) 13:27-36. doi:10.1038/ nrc3396

22. Bookout AL, Jeong Y, Downes M, Yu RT, Evans RM, Mangelsdorf DJ. Anatomical profiling of nuclear receptor expression reveals a hierarchical transcriptional network. Cell (2006) 126:789-99. doi:10.1016/j.cell.2006.06.049

23. Giguere V. Transcriptional control of energy homeostasis by the estrogenrelated receptors. Endocr Rev (2008) 29:677-96. doi:10.1210/er.2008-0017

24. Ijichi N, Ikeda K, Horie-Inoue K, Yagi K, Okazaki Y, Inoue S. Estrogen-related receptor alpha modulates the expression of adipogenesis-related genes during adipocyte differentiation. Biochem Biophys Res Commun (2007) 358:813-8. doi:10.1016/j.bbrc.2007.04.209

25. Kubo M, Ijichi N, Ikeda K, Horie-Inoue K, Takeda S, Inoue S. Modulation of adipogenesis-related gene expression by estrogen-related receptor gamma during adipocytic differentiation. Biochim Biophys Acta (2009) 1789:71-7. doi:10.1016/j.bbagrm.2008.08.012

26. Luo J, Sladek R, Carrier J, Bader JA, Richard D, Giguere V. Reduced fat mass in mice lacking orphan nuclear receptor estrogen-related receptor alpha. Mol Cell Biol (2003) 23:7947-56. doi:10.1128/MCB.23.22.7947-7956.2003

27. Villena JA, Kralli A. ERRalpha: a metabolic function for the oldest orphan. Trends Endocrinol Metab (2008) 19:269-76. doi:10.1016/j.tem. 2008.07.005

28. Luo J, Sladek R, Bader JA, Matthyssen A, Rossant J, Giguere V. Placental abnormalities in mouse embryos lacking the orphan nuclear receptor ERR-beta. Nature (1997) 388:778-82. doi:10.1038/42022 
29. Feng B, Jiang J, Kraus P, Ng JH, Heng JC, Chan YS, et al. Reprogramming of fibroblasts into induced pluripotent stem cells with orphan nuclear receptor Esrrb. Nat Cell Biol (2009) 11:197-203. doi:10.1038/ncb1827

30. Alaynick WA, Kondo RP, Xie W, He W, Dufour CR, Downes M, et al. ERRgamma directs and maintains the transition to oxidative metabolism in the postnatal heart. Cell Metab (2007) 6:13-24. doi:10.1016/j.cmet.2007.06.007

31. Cai Q, Lin T, Kamarajugadda S, Lu J. Regulation of glycolysis and the Warburg effect by estrogen-related receptors. Oncogene (2013) 32:2079-86. doi:10.1038/ onc.2012.221

32. Dufour CR, Wilson BJ, Huss JM, Kelly DP, Alaynick WA, Downes M, et al. Genome-wide orchestration of cardiac functions by the orphan nuclear receptors ERRalpha and gamma. Cell Metab (2007) 5:345-56. doi:10.1016/j.cmet. 2007.03.007

33. Ao A, Wang H, Kamarajugadda S, Lu J. Involvement of estrogen-related receptors in transcriptional response to hypoxia and growth of solid tumors. Proc Natl Acad Sci U S A (2008) 105:7821-6. doi:10.1073/pnas.0711677105

34. Stein RA, Chang CY, Kazmin DA, Way J, Schroeder T, Wergin M, et al. Estrogen-related receptor alpha is critical for the growth of estrogen receptornegative breast cancer. Cancer Res (2008) 68:8805-12. doi:10.1158/0008-5472. CAN-08-1594

35. Chang CY, Kazmin D, Jasper JS, Kunder R, Zuercher WJ, McDonnell DP. The metabolic regulator ERRalpha, a downstream target of HER2/IGF-1R, as a therapeutic target in breast cancer. Cancer Cell (2011) 20:500-10. doi:10.1016/ j.ccr.2011.08.023

36. Ariazi EA, Clark GM, Mertz JE. Estrogen-related receptor alpha and estrogenrelated receptor gamma associate with unfavorable and favorable biomarkers, respectively, in human breast cancer. Cancer Res (2002) 62:6510-8.

37. Jarzabek K, Koda M, Kozlowski L, Sulkowski S, Kottler ML, Wolczynski S. The significance of the expression of ERRalpha as a potential biomarker in breast cancer. J Steroid Biochem Mol Biol (2009) 113:127-33. doi:10.1016/j.jsbmb. 2008.12.005

38. Yang C, Zhou D, Chen S. Modulation of aromatase expression in the breast tissue by ERR alpha-1 orphan receptor. Cancer Res (1998) 58:5695-700.

39. Bianco S, Lanvin O, Tribollet V, Macari C, North S, Vanacker JM. Modulating estrogen receptor-related receptor-alpha activity inhibits cell proliferation. J Biol Chem (2009) 284:23286-92. doi:10.1074/jbc.M109.028191

40. Eichner LJ, Perry MC, Dufour CR, Bertos N, Park M, St-Pierre J, et al. miR-378(*) mediates metabolic shift in breast cancer cells via the PGC1beta/ERRgamma transcriptional pathway. Cell Metab (2010) 12:352-61. doi:10.1016/j.cmet.2010.09.002

41. Deblois G, St-Pierre J, Giguere V. The PGC-1/ERR signaling axis in cancer. Oncogene (2013) 32:3483-90. doi:10.1038/onc.2012.529

42. Kraus RJ, Ariazi EA, Farrell ML, Mertz JE. Estrogen-related receptor alpha 1 actively antagonizes estrogen receptor-regulated transcription in MCF-7 mammary cells. J Biol Chem (2002) 277:24826-34. doi:10.1074/jbc.M202952200

43. Stein RA, Gaillard S, McDonnell DP. Estrogen-related receptor alpha induces the expression of vascular endothelial growth factor in breast cancer cells. $J$ Steroid Biochem Mol Biol (2009) 114:106-12. doi:10.1016/j.jsbmb.2009.02.010

44. Fradet A, Sorel H, Bouazza L, Goehrig D, Depalle B, Bellahcene A, et al. Dual function of ERRalpha in breast cancer and bone metastasis formation: implication of VEGF and osteoprotegerin. Cancer Res (2011) 71:5728-38. doi:10.1158/0008-5472.CAN-11-1431

45. Lu D, Kiriyama Y, Lee KY, Giguere V. Transcriptional regulation of the estrogen-inducible pS2 breast cancer marker gene by the ERR family of orphan nuclear receptors. Cancer Res (2001) 61:6755-61.

46. Yu S, Wong YC, Wang XH, Ling MT, Ng CF, Chen S, et al. Orphan nuclear receptor estrogen-related receptor-beta suppresses in vitro and in vivo growth of prostate cancer cells via p21(WAF1/CIP1) induction and as a potential therapeutic target in prostate cancer. Oncogene (2008) 27:3313-28. doi:10.1038/ sj.onc. 1210986

47. Tiraby C, Hazen BC, Gantner ML, Kralli A. Estrogen-related receptor gamma promotes mesenchymal-to-epithelial transition and suppresses breast tumor growth. Cancer Res (2011) 71:2518-28. doi:10.1158/0008-5472.CAN-10-1315

48. Ijichi N, Shigekawa T, Ikeda K, Horie-Inoue K, Fujimura T, Tsuda H, et al. Estrogen-related receptor gamma modulates cell proliferation and estrogen signaling in breast cancer. J Steroid Biochem Mol Biol (2011) 123:1-7. doi:10. 1016/j.jsbmb.2010.09.002

49. Yu S, Wang X, Ng CF, Chen S, Chan FL. ERRgamma suppresses cell proliferation and tumor growth of androgen-sensitive and androgen-insensitive prostate cancer cells and its implication as a therapeutic target for prostate cancer. Cancer Res (2007) 67:4904-14. doi:10.1158/0008-5472.CAN-06-3855

50. Jemal A, Bray F, Center MM, Ferlay J, Ward E, Forman D. Global cancer statistics. CA Cancer J Clin (2011) 61:69-90. doi:10.3322/caac.20107

51. Perou CM, Sorlie T, Eisen MB, van de Rijn M, Jeffrey SS, Rees CA, et al. Molecular portraits of human breast tumours. Nature (2000) 406:747-52. doi:10.1038/ 35021093

52. Reis-Filho JS, Westbury C, Pierga JY. The impact of expression profiling on prognostic and predictive testing in breast cancer. J Clin Pathol (2006) 59:225-31. doi:10.1136/jcp.2005.028324

53. Rouzier R, Wagner P, Morandi P, Pusztai L. Gene expression profiling of primary breast cancer. Curr Oncol Rep (2005) 7:38-44. doi:10.1007/ s11912-005-0024-y

54. Sorlie T, Perou CM, Tibshirani R, Aas T, Geisler S, Johnsen H, et al. Gene expression patterns of breast carcinomas distinguish tumor subclasses with clinical implications. Proc Natl Acad Sci U S A (2001) 98:10869-74. doi:10.1073/ pnas. 191367098

55. Anderson WF, Chatterjee N, Ershler WB, Brawley OW. Estrogen receptor breast cancer phenotypes in the surveillance, epidemiology, and end results database. Breast Cancer Res Treat (2002) 76:27-36. doi:10.1023/A: 1020299707510

56. Niemeier LA, Dabbs DJ, Beriwal S, Striebel JM, Bhargava R. Androgen receptor in breast cancer: expression in estrogen receptor-positive tumors and in estrogen receptor-negative tumors with apocrine differentiation. Mod Pathol (2010) 23:205-12. doi:10.1038/modpathol.2009.159

57. Damber JE, Aus G. Prostate cancer. Lancet (2008) 371:1710-21. doi:10.1016/ S0140-6736(08)60729-1

58. Mohamed A, Krajewski K, Cakar B, Ma CX. Targeted therapy for breast cancer. Am J Pathol (2013) 183:1096-112. doi:10.1016/j.ajpath.2013.07.005

59. Swain SM, Baselga J, Kim SB, Ro J, Semiglazov V, Campone M, et al. Pertuzumab, trastuzumab, and docetaxel in HER2-positive metastatic breast cancer. N Engl J Med (2015) 372:724-34. doi:10.1056/NEJMoa1413513

60. Bauer KR, Brown M, Cress RD, Parise CA, Caggiano V. Descriptive analysis of estrogen receptor (ER)-negative, progesterone receptor (PR)-negative, and HER2-negative invasive breast cancer, the so-called triple-negative phenotype: a population-based study from the California Cancer Registry. Cancer (2007) 109:1721-8. doi:10.1002/cncr.22618

61. Criscitiello C, Azim HA Jr, Schouten PC, Linn SC, Sotiriou C. Understanding the biology of triple-negative breast cancer. Ann Oncol (2012) 23(Suppl 6):vi13-8. doi:10.1093/annonc/mds188

62. Reis-Filho JS, Tutt AN. Triple negative tumours: a critical review. Histopathology (2008) 52:108-18. doi:10.1111/j.1365-2559.2007.02889.x

63. Cancer Genome Atlas Network. Comprehensive molecular portraits of human breast tumours. Nature (2012) 490:61-70. doi:10.1038/nature11412

64. Perou CM. Molecular stratification of triple-negative breast cancers. Oncologist (2011) 16(Suppl 1):61-70. doi:10.1634/theoncologist.2011-S1-61

65. Heck S, Rom J, Thewes V, Becker N, Blume B, Sinn HP, et al. Estrogen-related receptor alpha expression and function is associated with the transcriptional coregulator AIB1 in breast carcinoma. Cancer Res (2009) 69:5186-93. doi:10. 1158/0008-5472.CAN-08-3062

66. Surowiak P, Materna V, Gyorffy B, Matkowski R, Wojnar A, Maciejczyk A, et al. Multivariate analysis of oestrogen receptor alpha, pS2, metallothionein and CD24 expression in invasive breast cancers. Br J Cancer (2006) 95:339-46. doi:10.1038/sj.bjc. 6603254

67. DeNardo DG, Cuba VL, Kim H, Wu K, Lee AV, Brown PH. Estrogen receptor DNA binding is not required for estrogen-induced breast cell growth. Mol Cell Endocrinol (2007) 277:13-25. doi:10.1016/j.mce.2007.07.006

68. Seely J, Amigh KS, Suzuki T, Mayhew B, Sasano H, Giguere V, et al. Transcriptional regulation of dehydroepiandrosterone sulfotransferase (SULT2A1) by estrogen-related receptor alpha. Endocrinology (2005) 146:3605-13. doi:10. 1210/en.2004-1619

69. Apak TI, Duffel MW. Interactions of the stereoisomers of alphahydroxytamoxifen with human hydroxysteroid sulfotransferase SULT2A1 and rat hydroxysteroid sulfotransferase STa. Drug Metab Dispos (2004) 32:1501-8. doi:10.1124/dmd.104.000919

70. Suzuki T, Miki Y, Moriya T, Shimada N, Ishida T, Hirakawa H, et al. Estrogen-related receptor alpha in human breast carcinoma as a potent prognostic factor. Cancer Res (2004) 64:4670-6. doi:10.1158/0008-5472. CAN-04-0250 
71. Galindo CL, McCormick JF, Bubb VJ, Abid Alkadem DH, Li LS, McIver LJ, et al. A long AAAG repeat allele in the 5' UTR of the ERR-gamma gene is correlated with breast cancer predisposition and drives promoter activity in MCF-7 breast cancer cells. Breast Cancer Res Treat (2011) 130:41-8. doi:10. 1007/s10549-010-1237-9

72. Siegel R, Naishadham D, Jemal A. Cancer statistics, 2013. CA Cancer J Clin (2013) 63:11-30. doi:10.3322/caac.21166

73. Nyquist MD, Dehm SM. Interplay between genomic alterations and androgen receptor signaling during prostate cancer development and progression. Horm Cancer (2013) 4:61-9. doi:10.1007/s12672-013-0131-4

74. Huggins C, Hodges CV. Studies on prostatic cancer. I. The effect of castration, of estrogen and androgen injection on serum phosphatases in metastatic carcinoma of the prostate. CA Cancer J Clin (1972) 22:232-40.

75. Fujimura T, Takahashi S, Urano T, Ogawa S, Ouchi Y, Kitamura T, et al. Differential expression of estrogen receptor beta (ERbeta) and its C-terminal truncated splice variant ERbetacx as prognostic predictors in human prostatic cancer. Biochem Biophys Res Commun (2001) 289:692-9. doi:10.1006/bbrc. 2001.6038

76. Ho SM. Estrogens and anti-estrogens: key mediators of prostate carcinogenesis and new therapeutic candidates. J Cell Biochem (2004) 91:491-503. doi:10.1002/ jcb. 10759

77. Cheung CP, Yu S, Wong KB, Chan LW, Lai FM, Wang X, et al. Expression and functional study of estrogen receptor-related receptors in human prostatic cells and tissues. J Clin Endocrinol Metab (2005) 90:1830-44. doi:10.1210/jc. 2004-1421

78. Fujimura T, Takahashi S, Urano T, Kumagai J, Ogushi T, Horie-Inoue K, et al. Increased expression of estrogen-related receptor alpha (ERRalpha) is a negative prognostic predictor in human prostate cancer. Int J Cancer (2007) 120:2325-30. doi:10.1002/ijc. 22363

79. Fujimura T, Takahashi S, Urano T, Ijichi N, Ikeda K, Kumagai J, et al. Differential expression of estrogen-related receptors beta and gamma
(ERRbeta and ERRgamma) and their clinical significance in human prostate cancer. Cancer Sci (2010) 101:646-51. doi:10.1111/j.1349-7006. 2009.01451.x

80. Suetsugi M, Su L, Karlsberg K, Yuan YC, Chen S. Flavone and isoflavone phytoestrogens are agonists of estrogen-related receptors. Mol Cancer Res (2003) 1:981-91.

81. Tremblay GB, Kunath T, Bergeron D, Lapointe L, Champigny C, Bader JA, et al. Diethylstilbestrol regulates trophoblast stem cell differentiation as a ligand of orphan nuclear receptor ERR beta. Genes Dev (2001) 15:833-8. doi:10.1101/ gad. 873401

82. Coward P, Lee D, Hull MV, Lehmann JM. 4-Hydroxytamoxifen binds to and deactivates the estrogen-related receptor gamma. Proc Natl Acad Sci U S A (2001) 98(15):8880-4. doi:10.1073/pnas.151244398

83. Tremblay GB, Bergeron D, Giguere V. 4-Hydroxytamoxifen is an isoformspecific inhibitor of orphan estrogen-receptor-related (ERR) nuclear receptors beta and gamma. Endocrinology (2001) 142(10):4572-5. doi:10.1210/en. 142.10.4572

84. Chao WR, Amin K, Shi Y, Hobbs P, Tanabe M, Tanga M, et al. SR16388: a steroidal antiangiogenic agent with potent inhibitory effect on tumor growth in vivo. Angiogenesis (2011) 14(1):1-16. doi:10.1007/s10456-010-9191-z

Conflict of Interest Statement: The authors declare that the research was conducted in the absence of any commercial or financial relationships that could be construed as a potential conflict of interest.

Copyright (C) 2015 Misawa and Inoue. This is an open-access article distributed under the terms of the Creative Commons Attribution License (CC BY). The use, distribution or reproduction in other forums is permitted, provided the original author(s) or licensor are credited and that the original publication in this journal is cited, in accordance with accepted academic practice. No use, distribution or reproduction is permitted which does not comply with these terms. 